opiate agonist, opiate effects might be expected and serious side effects should be reversible with an opiate antagonist such as naloxone.

Weaver et al. make a somewhat discrepant and misleading statement regarding the doses of loperamide that we administered to our patients with protracted diarrhoea: 'although 5 out of the 6 children described received less than $1 \mathrm{mg} / \mathrm{kg} / \mathrm{day}$, one was treated with $3.8 \mathrm{mg} / \mathrm{kg} /$ day'. The dose of loperamide in the 5 children was calculated according to expected body weight whereas in the 1 patient referred to the dose was calculated according to actual body weight. The dose for expected body weight in the latter child was similar $(1.4 \mathrm{mg} / \mathrm{kg} /$ day body weight) to that of the other 5 children.

\section{Surgical treatment in neonatal congenital heart disease}

Sir,

We read with great interest the paper by Bove et al. ${ }^{1}$ and welcome an all too rare total review of a challenging group of patients. However, as their $57 \%$ hospital mortality for patients undergoing procedures using cardiopulmonary bypass may discourage referring

Table 1 Neonates undergoing operation from January 1977-February 1982

\begin{tabular}{|c|c|c|}
\hline & \multirow{2}{*}{$\begin{array}{l}\text { No of } \\
\text { patients } \\
(\%)\end{array}$} & \multirow{2}{*}{$\frac{\text { Early mortality }}{\text { No }(\%)}$} \\
\hline & & \\
\hline $\begin{array}{l}\text { Frocedures using cardiopulmonary bypass } \\
\text { Non bypass procedures for } \\
\text { indaequate pulmonary blood flow }\end{array}$ & $\begin{array}{l}31(36) \\
22(25)\end{array}$ & $\begin{array}{r}11(35 \cdot 5) \\
4(18 \cdot 2)\end{array}$ \\
\hline $\begin{array}{l}\text { Non bypass procedure for } \\
\text { increased pulmonary blood flow/ } \\
\text { inadequate mixing }\end{array}$ & $12(14)$ & $0(0)$ \\
\hline Coarctation syndrome & $22(25)$ & $3(13 \cdot 6)$ \\
\hline Total & 87 & $18(20 \cdot 7)$ \\
\hline
\end{tabular}

paediatricians, it prompted us to examine our own results in this age group during the period January 1977 to February 1983. Like the group from the Hospital for Sick Children, Great Ormond Street, we were often dealing with desperate near moribund infants with perhaps uncorrectable lesions in some cases.

Table 1 shows the incidence and early mortality in the same 4 groups of patients that they reported. ${ }^{1}$ Our group of patients undergoing operation using cardiopulmonary bypass represented $36 \%$ of the total compared with their $19 \%$ and reflects our practice of offering corrective rather than palliative surgical procedures wherever possible. This increase was mainly at the expense therefore of the group with inadequate pulmonary blood flow who underwent a procedure without cardiopulmonary bypass.

Table 2 lists the 31 procedures which we performed using cardiopulmonary bypass and surface cooling. The overall mortality of $35.5 \%$ in these patients is less than the $57.5 \%$ reported by Bove et al. but it is only fair to point out that our series covered a more recent period of time. The other striking difference is that in contrast to our practice they did not attempt correction of Fallot's Tetralogy or pulmonary atresia with intact septum.

Our overall early mortality of $27.7 \%$ and that of $31.3 \%$ reported by Bove et al. indicate that most babies with congenital heart disease presenting in the first 4 weeks of life can be saved by surgery. However, in order to achieve this it is essential that patients are referred promptly under the best possible conditions to a few selected centres experienced in neonatal cardiac surgery. These infants can usually travel safely even over long distances, particularly with the help of prostaglandin management of the ductus arteriosus and appropriate cardiorespiratory support. If such infants are treated in centres specialising in this type of surgery results can still improve greatly, but we deprecate initial management in less experienced units where unnecessary palliative procedures rather than correction may be performedoften producing an unacceptably high mortality or subsequently more difficult anatomical problems to correct.

Table 2 Procedures in 31 patients using cardiopulmonary bypass

\begin{tabular}{|c|c|c|c|c|}
\hline \multirow[t]{2}{*}{ Diagnosis } & \multirow{2}{*}{$\begin{array}{l}\text { No of } \\
\text { patients }\end{array}$} & \multirow[t]{2}{*}{ Procedure } & \multicolumn{2}{|c|}{ Mortality } \\
\hline & & & No & $\%$ \\
\hline TAPVD & 2 & Complete repair & 0 & 0 \\
\hline Truncus arteriosus & 3 & Complete repair & 1 & 33 \\
\hline Pulmonary stenosis & 2 & Valvotomy and transannular patch & 1 & 50 \\
\hline Pulmonary atresia/VSD & 1 & Outflow tract patch only & 1 & 100 \\
\hline Pulmonary atresia/no VSD & 3 & Complete repair & 2 & 67 \\
\hline Tetralogy of Fallot & 2 & Complete repair & 0 & 0 \\
\hline Complete TGA & $\overline{7}$ & Mustard & 1 & 14 \\
\hline VSD, interrupted Ao arch & 3 & Closure of VSD repair of arch & 1 & 33 \\
\hline VSD, hypoplastic Ao arch & 2 & Closure of VSD repair of arch & 0 & 0 \\
\hline VSD & 3 & Closure of VSD & 1 & 33 \\
\hline Complete AV canal & 1 & Complete repair & 1 & 100 \\
\hline Hypoplastic left heart syndrome & 1 & $\begin{array}{l}\text { Septectomy, anastomosis of Ao and MPA, } \\
\text { individual PA's banded }\end{array}$ & 1 & 100 \\
\hline Ebstein's anomaly of tricuspid valve & 1 & Tricuspid valve replacement & 1 & 100 \\
\hline Total & 31 & & 11 & $35 \cdot 5$ \\
\hline
\end{tabular}

TAPVD $=$ total anomalous pulmonary venous drainage; VSD = ventricular septal defect; TGA $=$ transposition of the great arteries; Ao = aorta; $\mathrm{AV}=$ atrioventricular; MPA $=$ main pulmonary artery. 
Reference

1 Bove EL, Bull C, Stark J, de Leval M, Macartney FJ, Taylor JFN. Congenital heart disease in the neonate: results of surgical treatment. Arch Dis Child 1983; 58: 137-41.

B R Keeton AND J L MonRo Wessex Cardiac and Thoracic Centre, Southampton General Hospital, Shirley, Southampton SO9 $4 X Y$

\section{Healthier children-thinking prevention}

Sir,

In your annotation of February 1983, you published 2 comments from wise paediatricians on the Royal College of General Practitioners' working party report 'Healthier children-thinking prevention'. May I take up Professor Court's comment on clinical medical officers (CMOs) who are 'now insisting on remaining an independent third force'. I would hope that he of all people would see this 'insistence' for what it is. It is a BMA campaign orchestrated by a powerful minority of community physicians, who know that the speciality of community medicine would be a little fish in a big consultants' pool were it not for the numbers of CMOs at present at their beck and call. The CMOs who support the 'third force' are largely those trained in public health who despite their considerable experience have an insecure footing in community paediatrics. (Please note, these doctors are 'inappropriately trained' for some of the work and not, as so often stated, 'inadequately trained'. There is an important difference). They are often also CMOs working in the areas where general practice provides for the children and their families a mockery of a service for treatment let alone prevention.

There remain then a large number of CMOs, including most of the younger doctors trained in paediatrics, who will continue to support integration-they may even be the majority, and if silent, certainly not inactive. What is needed immediately is the hand of welcome from general practice, and the admission that in some places an interim third force (of which general practice could be a part) may be the only way of providing a good service for children. Hospital paediatricians have been rather more forthcoming. Sometimes, if only because the exigencies of their own service have forced this upon them. Once the rotation posts between senior house officer and CMO have been developed, however, all are agreed that the advantages on all sides are so great that there is no going back.

But this is not enough. Who are to be the trainers for the registrars and senior registrars who may soon be working in the community under a consultant paediatrician with special responsibility for the community? Who will train the general practioners? May I suggest that the greatest contribution paediatricians could make now would be to accept that the 'real' SCMOs (not those who do the same work as CMOs but just get paid more for time served) have an important role in training? They need to be accepted into departments of paediatrics, and given the opportunity to teach the work they know and the skills they have developed-educational medicine, child abuse outside the hospital, diagnosis and management of all kinds of handicap, and medical problems of social deprivation and inequality. Some of these SCMOs with paediatric membership could with a little support from hospital consultant paediatricians, be accredited as 'specialists' if this would make them more respectable as teachers in the eyes of their academic colleagues.

The alternative then to a third force is in the hands (and almost in the grasp) of paediatricians and general practitioners. If a third force is needed in geriatrics or psychiatry, then this is another matter and of no concern to paediatricians who need to rescue 'child health' from such discussions. Given the will, they could do it, and who knows perhaps even bring the 'vision and reality' a few important steps closer together.

ShelaGh TYRRELL Paddington and North Kensington Health Authority, 14 Bishops Bridge Road, London W2 6AF

\section{Choosing investigations}

$\mathrm{Sir}$,

I was delighted to see the annotation by Professor Tom Sherwood in your March 1983 edition. I am a strong proponent of close cooperation between imaging departments and clinicians and believe in the ability of those concerned with imaging techniques to choose the relevant investigation with full knowledge of the clinical problem. I believe that in paediatric radiology and imaging we have achieved this sort of liaison, at least in the children's hospitals, and with emphasis being placed on basic training in paediatric radiology for all registrars and senior registrars in radiodiagnosis, I would hope that this situation will exist in relation to all paediatric units. Finally I would ask whether Professor Sherwood's annotation appeared in the correct journal or was he preaching to the already converted? I should very much appreciate your readers' comments.

R K LEVICK

Chairman, Paediatric Radiology Group, Royal College of Radiologists, The Children's Hospital, Sheffield 10

\section{In vitro anorectal manometry?}

Sir,

I have read with interest the paper by Molnar et al. entitled, "Anorectal manometry results in defecation disorders'. I cannot believe that your illustrious editorial board missed such a splendid double entendre and must assume that they let it pass as a rival to the famous wartime headline, 'French thrust bottles up German rear'. I look forward to more humour in the Archives.

GoRDON STARK 33 Frogston Road West, Edinburgh 